\title{
DESIGN AND EVALUATION OF FOOD GRADE WAX MATRIX SUSTAINED RELEASE MINI-TABLETS OF MONTELUKAST SODIUM
}

\author{
DESHPANDE AH ${ }^{1}$, WASULE ${ }^{2}$ \\ ${ }^{1}$ Department of Pharmaceutics, Gurunanak College of Pharmacy, Nagpur, Maharashtra, India. ${ }^{2}$ Department of Cosmetic Technology, \\ Lady Amritabai Daga for Women of Arts, Commerce and Science and Smt. Ratnidevi Purohit College of Homescience \& Homescience \\ Technology, Nagpur, Maharashtra, India. Email: amarhdeshpande@gmail.com
}

Received: 26 December 2016, Revised and Accepted: 16 January 2017

ABSTRACT

Objective: The objective of this study is to formulate a tablet that fits in the size range of mini-tablets using wax matrix forming substances, allows variation of drug dose and study of drug release kinetics of the dosage form.

Methods: The blends of drug with glyceryl monostearate, purified rice bran wax and carnauba wax that renders the waxes food grade, were prepared and evaluated for precompression characteristics. The blends were compressed into mini-tablets having desirable physical characteristics and were subjected to tests such as weight variation and friability. The tablets were subjected to drug dissolution test and the release parameters were mathematically treated for order and mechanism of drug release.

Results: The tablets complied with the pharmacopoeial standards of physical characteristics. The release was satisfactorily sustained (up to 10 hrs) by carnauba wax and rice bran wax, but not by glyceryl monostearate (only up to $4 \mathrm{hrs).} \mathrm{The} \mathrm{release} \mathrm{followed} \mathrm{a} \mathrm{zero} \mathrm{order} \mathrm{with} \mathrm{super} \mathrm{Case} \mathrm{II} \mathrm{transport}$ being the major mechanism of drug release.

Conclusion: Wax matrix formers were satisfactorily used for sustained drug release mini-tablets. The tablets had good physical characteristics with major mechanism of drug release being super Case II transport.

Keywords: Wax matrix, Sustained release, Mini-tablets, Montelukast sodium.

(C) 2017 The Authors. Published by Innovare Academic Sciences Pvt Ltd. This is an open access article under the CC BY license (http://creativecommons. org/licenses/by/4. 0/) DOI: http://dx.doi.org/10.22159/ajpcr.2017.v10i4.16788

\section{INTRODUCTION}

The lipids we use in preparation of pharmaceutical formulations have their origin in the food stuff used. The lipids attract attention as they can help improve pharmaceutical product cycle and are cost-effective. They are used in various drug delivery systems intended to improve oral bioavailability and esthetics of the drug [1].

Mini-tablets are multiple unit dosage forms developed to retain advantages of formulations like pellets that include uniformity of drug release, less tendency of dose dumping, and greater patience compliance. However, mini-tablets score more advantages such as improved mechanical strength, more dose loading capacity, and uniformity of size and shape. Mini-tablets have a diameter in the range of $2 \mathrm{~mm}$ and can be presented filled in capsules like pellets or separately which serves an advantage of dose variation with the age and clinical condition of the patient [2].

Montelukast sodium, a leukotriene receptor antagonist, blocks the action of leukotriene D4 on the cysteinyl leukotriene receptor CysLT1 in lungs and bronchial tubes to decrease bronchoconstriction and inflammation. It is used in treatment of asthma and for symptomatic relief from seasonal allergies. Montelukast sodium is hygroscopic, optically active, white to off-white powder, freely soluble in ethanol, methanol, and water and practically insoluble in acetonitrile with a melting point $135.5^{\circ} \mathrm{C}$ and half-life $2.2-5.5 \mathrm{hrs}$ [3].

The drug dispersed evenly in the lipid matrix diffuses when exposed to the dissolution medium. The drug on the surface dissolves forming pores for the dissolution medium to penetrate. Then the drug dissolves. Release follows square of time release kinetics. In case of a highly soluble drug such as Montelukast sodium, or large amount of soluble product in the matrix, the porosity of the matrix increases with dissolution time [4].

Erosion and/or partial solubilization may occur during the dissolution depending on the composition of the fatty compounds. In general, the erosion or solubilization of triglycerides is achieved in vivo by enzymes which hydrolyze the ester bonds of triglycerides. There are many enzymes called esterases, lipases which hydrolyze the ester bonds of triglycerides. These compounds can then be easily absorbed through the intestinal wall. However, the very long chains, C16-C22 (in case of glyceryl behenate, cetyl alcohol, and glyceryl monostearate) are hardly hydrolyzed, and hence, poor absorption through the intestinal wall [5].

The objective, therefore, is to formulate a tablet that fits in the size range of mini-tablets, allows variation of drug dose and study of drug release kinetics of the dosage form.

\section{METHODS}

Montelukast sodium was obtained as a gift sample from Zim Laboratories, Nagpur, pharmaceutical grade microcrystalline cellulose, glyceryl monostearate, magnesium stearate, Talc were obtained from HiMedia, Mumbai, polyethylene glycol (PEG) 4000, PEG 6000, carnauba wax and PEG 500 were obtained from Research Laboratories, Mumbai. Rice bran wax was procured from Maheshwari rice mills, Gondia. Solvents were obtained from SD Fine Chemicals and were distilled before use.

Purification of crude rice bran wax to get food grade rice bran wax [6]

The purification of rice bran wax involves two-step process commencing from the removal of residual oil with the help of solvent 
n-hexane followed by isopropanol. The defatted wax is then bleached with sodium borohydride to yield a white compound which can be used further. About $100 \mathrm{~g}$ of crude rice bran wax was refluxed with about $1 \mathrm{~L}$ of n-hexane at about $50^{\circ} \mathrm{C}$ for $3 \mathrm{hrs}$. The mixture was cooled to about $20^{\circ} \mathrm{C}$ and was filtered and dried. This dried wax, about $50 \mathrm{~g}$ was then refluxed with about $500 \mathrm{ml}$ of isopropyl alcohol at about $80^{\circ} \mathrm{C}$ for $3 \mathrm{hrs}$ and was then cooled to about $20^{\circ} \mathrm{C}$ and the residue was filtered. Most of the oil content is removed by n-hexane washing and remaining polar oils and lipids are washed in the isopropyl alcohol washing to yield a brownish wax which is harder to feel.

\section{Bleaching of the defatted wax}

The color is due to the presence of resinous matter which can be removed by bleaching. The defatted wax, about $50 \mathrm{~g}$ is refluxed with isopropyl alcohol at about $80^{\circ} \mathrm{C}$ in a two neck round bottomed flask fitted with a rubber cork. When the desired temperature is reached, the wax is bleached by drop wise addition of $10 \%$ solution of sodium borohydride. The process yields a separate layer of resinous matter, being more polar in nature, separates and the wax remains in the molten state. The mixture is filtered when hot to separate resinous matter and the white wax separates as solid crystals from the filtrate on cooling

The rice bran wax was evaluated for its content and quality. By same procedure, carnauba wax was also purified and bleached.

\section{Preparation of blends}

Four different wax matrix formers were used namely PEG 4000, GMS, carnauba wax (purified and bleached), and rice bran wax (purified and bleached) in different batches and their influence on the tablet properties was compared. The wax matrix former was passed through a sieve no. 30 (ASTM). The drug and the other excipients were added after being passed through sieve no. 80 (ASTM) to the wax matrix former.

Evaluation of blends for compressed mini-tablets [7-12]

The blends were evaluated for their compressibility by measuring the angle of repose, Carr's index and Hauser's ratio.

\section{Angle of repose}

It is determined by allowing a powder to flow through a funnel and fall freely onto a surface. Further addition of powder is stopped as soon as the pile touches the tip of the funnel. A circle is drawn around the pile without disturbing it. The height and diameter of the resulting cone are measured. The same procedure is repeated three times and the average value is taken. Angle of repose is calculated using the following equation:

Tan $\theta=h / r$

Where $h=$ Height of the powder cone; $r=$ Radius of the powder.

\section{Bulk density}

Unless otherwise specified, pass a quantity of material sufficient to complete the test through a $1.00 \mathrm{~mm}$ (no. 18 ASTM) screen to break up agglomerates that may have formed during storage. Into a dry $250 \mathrm{ml}$ cylinder introduce, without compacting, approximately $100 \mathrm{~g}$ of the test sample $(M)$ weighed with $0.1 \%$ accuracy. If it is not possible to use $100 \mathrm{~g}$, the amount of the test sample and the volume of the cylinder may be modified. Select a sample mass having an untapped apparent volume of $150-250 \mathrm{ml}$. A $100 \mathrm{ml}$ cylinder is used for apparent volumes between 50 and $100 \mathrm{ml}$. Fill the cylinder carefully. Carefully level the powder without compacting, if necessary, and read the unsettled apparent volume $\left(V_{o}\right)$. Calculate the bulk density, in $\mathrm{g} / \mathrm{ml}$, using the formula:

Bulk density $=\frac{M}{V_{0}}$

Tapped density [11]

Accurately weighed quantity of powder is introduced into a measuring cylinder. Mechanically tap the cylinder containing the sample by raising the cylinder and allowing it to drop under its own weight using a suitable mechanical tapped density tester at a nominal rate of 300 drops/minutes. Tap the cylinder 500 times and measure the tapped volume $\left(V_{a}\right)$. Repeat the operation for an additional 750 tapings and again measure the tapped volume as $\left(V_{b}\right)$.

If the difference between $V_{a}$ and $V_{b}$ is $<2 \%, V_{b}$ is the final tapped volume $(V f)$ If the difference is higher, repeat the tapings for an additional 1250 times, and then, the tapped density can be calculated using the following formula (United States pharmacopoeia, 2004).

Tapped density $=\frac{M}{V_{f}}$

Where $M$ = Weight of the sample taken; $V_{f}=$ Final tapped volume.

\section{Carr's index and Hausner's ratio [11]}

The compressibility index of granules can be determined using Carr's compressibility index, and can be determined by the following formula: The compressibility index of granules can be determined using Carr's compressibility index, and can be determined by the following formula:

The compressibility index is calculated by the formula:

Compressibility index $=\frac{\left(\rho_{t}-\rho_{o}\right)}{\rho_{t}} \times 100$

Hausner's ratio is calculated as:

Hausner's ratio $=\frac{\rho_{t}}{\rho_{o}}$

The compressibility index is evaluated for the interpretation of the flow of the granules. The relationship is presented in Table 1.

Size distribution of mixture was checked and the blends were compressed in Cemach make R\&D press at 5 tons pressure.

\section{Evaluation of mini-tablets [12]}

The mini-tablets were evaluated for parameters such as weight variation, thickness, hardness, friability, disintegration time, dissolution time, taste and mouth feel.

a. Tablet thickness: Thickness was measured using vernier caliper.

b. Weight variation: Randomly selected 20 tablets from the lot were weighted individually to check for weight variation. Weight variation specification as per IP is shown in Table 2 .

c. Friability: Preweighed tablets were placed in the Roche Friabilator for 100 revolutions. At the end of test tablets were dusted and

Table 1: Interpretation of Carr's index and Hausner's ratio

\begin{tabular}{lll}
\hline Carr's index & Flowability & Hausner's ratio \\
\hline 10 & Excellent & $1.00-1.11$ \\
$11-15$ & Good & $1.12-1.18$ \\
$16-20$ & Fair & $1.19-1.25$ \\
$21-25$ & Passable & $1.26-1.34$ \\
$26-31$ & Poor & $1.35-1.45$ \\
$32-37$ & Very poor & $1.46-1.59$ \\
$<40$ & Very very poor & $>1.60$ \\
\hline
\end{tabular}

Table 2: Weight variation test specifications as per IP

\begin{tabular}{ll}
\hline Average weight of tablet & \% deviation \\
\hline $80 \mathrm{mg}$ or less & \pm 10 \\
$>80 \mathrm{mg}$ but $<250 \mathrm{mg}$ & \pm 7.5 \\
$250 \mathrm{mg}$ or more & \pm 5 \\
\hline
\end{tabular}


reweighed; the loss in the weight of tablet is the measure of friability and is expressed in percentage as:

$\%$ Friability $=1-($ loss in weight $/$ Initial weight $) \times 100$

Limit-less than $1 \%$

d. Hardness test: Tablet hardness was measured with Monsanto hardness tester. A tablet was placed in the hardness tester and load required to crush the tablet was measured. The force is measured in $\mathrm{kg}$ and the hardness of about $5-8 \mathrm{~kg} / \mathrm{cm}^{2}$ was considered to be satisfactory for uncoated tablets.

e. Dissolution test: The dissolution method for oral disintegrating tablets was the same as that of conventional tablets. USP 2 paddle apparatus is most suitable and common choice for dissolution test of oral disintegrating tablets, where the paddle speed is $50 \mathrm{rpm}$ is used.

f. Mathematical modeling of drug release: To determine the drug release rates, the results of the dissolution tests were fitted to the following equations. A regression analysis was used to obtain the release constant $\mathrm{K}$ and correlation coefficients $\mathrm{r}$ for each model. The correlation coefficients for the best statistical fit were used as the main criterion to evaluate the model.

i. Zero-order model [13]

$C=\left(K_{0} t\right)$

$C=\%$ drug release, $K_{0}=$ Zero-order rate constant expressed in units of concentration/time $(t)$.

ii. First-order model [13]

$$
\log C_{r}=\log C_{0}-\frac{K_{1} t}{2.303}
$$

$C_{r}=\%$ remaining, $C_{0}=$ Initial concentration of drug, $K_{1}=$ First-order constant, $t=$ Time.

iii. T. Higuchi model [14]

If the drug is dispersed in homogenous matrix instead of being complexed or dissolved, the release kinetics are altered. Higuchi developed a mathematical model for analysis of such system: The release of dispersed drugs by diffusion from a stationary matrix such as ointment. The expression of drug released per unit area from slab takes form:

$M_{t}=\left(C_{s} D(2 A-C) t\right)^{1 / 2}$

Where $M_{t}$ is the amount of drug released per unit area at time $t$, $D$ and $C_{s}$ are the diffusion coefficient and solubility of the drug in the polymer, respectively, and $A$ is the concentration of the drug initially present in the matrix. When $A>>C_{s^{\prime}}$, the equation reduces to:

$$
M_{t}=\left(2 C_{s} D A_{t}\right)^{1 / 2}
$$

This is known as Higuchi's square root of $t$ equation, which describes linear relationship between the amount of drug released and $t_{1 / 2}$ provided $D, A$ and $C_{s}$ are constant. It was indicated that the model would only be suitable for systems where $A$ exceeds $C$ by a factor of three or more and it has been reported for polymer dispersions containing as less as $1 \%$ of drug. In this model, it is assumed that the solid rug dissolves from the surface layer and this layer becomes exhausted of drug particles.

iv. Korsmeyer and Peppas model [15-17]

Korsmeyer et al. derived a simple relationship, which described drug release from a polymeric system:

$$
\frac{M_{t}}{M_{\infty}}=k \cdot t^{n}
$$

Where $M_{t} / M_{\mathrm{a}}$ is the fraction of drug released, $t$ is the release time, $k$ is a kinetic constant (with units of $t^{n}$ ) incorporating structural and geometric characteristics of the release device and $n$ is the release exponent indicative of the mechanism of release. This equation can be used to analyze the first $60 \%$ of a release curve where the release is linearly related to $t^{n}$, regardless of geometric shape. Peppas (1985), Sahlin and Peppas (1989), have shown also that two competing release mechanisms, a Fickian diffusional release and a Case II relaxational release, are the limits of this phenomenon.
Fickian diffusional release occurs by the usual molecular diffusion of the drug due to a chemical potential gradient. Case II relaxational release is the drug transport mechanism associated with stresses and state-transition in hydrophilic glassy polymers, which swell in water or biological fluids. This term also includes polymer disentanglement and erosion. The value of the exponent for Case II transport mechanism is twice that of pure Fickian diffusional mechanism.

\section{RESULTS}

Rice bran wax and carnauba wax were evaluated for their physicochemical properties as per the methods specified in literature and the results are recorded as follows in Table 3 .

\section{Evaluation of granules}

The formulation blends were considerably different in their physical and flow properties. The flow properties and packing properties of the blends show desirable characteristics for compression (Table 4)

\section{Evaluation of mini-tablets}

The mini-tablets were prepared by direct compression of blends using Cemach make R\&D press. The thickness and hardness of the tablets was measured during compression regularly. The tablets were subjected to weight variation, friability, and assayed for drug content and the results are reported in Table 5

\section{Dissolution profile}

The dissolution profile of mini-tablets is recorded in the following Table 6 .

\section{Drug release kinetic studies}

Table 7 shows drug release kinetic studies.

\section{DISCUSSION}

According to the physicochemical properties of the waxes recorded in Table 3, it can be concluded that the purification process rendered the waxes food-grade [6]. The different blends were prepared as per amounts specified in Table 8. The blends were evaluated for compressibility and other properties as per the values and methods given in Tables 1, 2, 9 and 10. From the precompression parameters given in Tables 4 and 11, it is clear that the granules were suitable for compression. They possessed acceptable flow properties and hence

\begin{tabular}{|c|c|c|c|c|}
\hline S. No. & $\begin{array}{l}\text { Physicochemical } \\
\text { properties }\end{array}$ & $\begin{array}{l}\text { Carnauba } \\
\text { wax }\end{array}$ & $\begin{array}{l}\text { Rice bran } \\
\text { wax }\end{array}$ & $\begin{array}{l}\text { Glyceryl } \\
\text { monostearate }\end{array}$ \\
\hline 1 & Melting point ${ }^{\mathrm{a}}$ & $84^{\circ} \mathrm{C} \pm 0.2$ & $81^{\circ} \mathrm{C} \pm 0.2$ & $56^{\circ} \mathrm{C} \pm 0.2$ \\
\hline 2 & Acid value $^{\mathrm{b}}$ & $10 \pm 0.1$ & $1.8 \pm 0.1$ & $6 \pm 0.3$ \\
\hline 3 & $\begin{array}{l}\text { Saponification } \\
\text { value }^{\text {b }}\end{array}$ & $85 \pm 1.2$ & $81 \pm 0.5$ & $158 \pm 0.4$ \\
\hline 4 & Iodine value $\mathrm{e}^{\mathrm{b}}$ & $10 \pm 0.1$ & $8.1 \pm 0.3$ & $3 \pm 0.2$ \\
\hline
\end{tabular}
were considered for compression. Carnauba wax and rice bran wax are

Table 3: Physicochemical properties* of wax matrix substances

Table 4: Flow property of formulations from angle of repose*

\begin{tabular}{lll}
\hline Formulations & Angle of repose $(\boldsymbol{\theta})$ & Flowability \\
\hline F1 & $24^{\circ} 58^{\prime} \pm 1.2$ & Excellent \\
F2 & $26^{\circ} 31^{\prime} \pm 1.4$ & Excellent \\
F3 & $29^{\circ} 13^{\prime} \pm 0.3$ & Excellent \\
F4 & $27^{\circ} 15^{\prime} \pm 1.2$ & Excellent \\
F5 & $24^{\circ} 48^{\prime} \pm 2.3$ & Excellent \\
F6 & $25^{\circ} 21^{\prime} \pm 1.9$ & Excellent \\
\hline
\end{tabular}

*The values in the table designate average values of $n=6$ with \pm standard deviation values 
Table 5: Quality control tests* of mini-tablets

\begin{tabular}{|c|c|c|c|c|c|}
\hline FC & Hardness $\left(\mathrm{kg} / \mathrm{cm}^{2}\right)$ & Thickness (mm) & Friability\% & Drug content (\%) & Weight variation test IP \\
\hline $\mathrm{F} 1$ & $4.2 \pm 1.2$ & $3.12 \pm 1.2$ & $0.54 \pm 0.2$ & $98.22 \pm 0.7$ & PASS \\
\hline $\mathrm{F} 2$ & $4.1 \pm 0.3$ & $3.23 \pm 1.7$ & $0.62 \pm 0.8$ & $99.33 \pm 1.2$ & PASS \\
\hline F3 & $4.3 \pm 1.8$ & $3.42 \pm 2.03$ & $0.74 \pm 1.3$ & $98.18 \pm 0.4$ & PASS \\
\hline F4 & $4.8 \pm 1.3$ & $3.12 \pm 0.4$ & $0.58 \pm 2.1$ & $98.35 \pm 0.2$ & PASS \\
\hline F5 & $4.7 \pm 2.1$ & $3.21 \pm 1.3$ & $0.63 \pm 1.5$ & $98.24 \pm 1.1$ & PASS \\
\hline F6 & $4.8 \pm 2.3$ & $3.23 \pm 0.2$ & $0.71 \pm 1.2$ & $98.25 \pm 1.3$ & PASS \\
\hline
\end{tabular}

*The values in the table designate average values with \pm standard deviation values

Table 6: Average cumulative drug release profiles of Montelukast formulations

\begin{tabular}{|c|c|c|c|c|c|c|}
\hline \multirow[t]{2}{*}{ Time (hr) } & \multicolumn{6}{|c|}{ Average $\%$ cumulative drug release time points of different batches $( \pm \operatorname{SD}$ of $n=6)$} \\
\hline & F1 & F2 & F3 & F4 & F5 & F6 \\
\hline 1 & $9.72 \pm(1.05)$ & $5.17 \pm(0.68)$ & $29.52 \pm(0.79)$ & $24.28 \pm(0.64)$ & $9.42 \pm(1.2)$ & $5.06 \pm(0.17)$ \\
\hline 2 & $19.27 \pm(0.78)$ & $15.05 \pm(0.46)$ & $56.41 \pm(1.95)$ & $51.97 \pm(2.40)$ & $20.98 \pm(0.8)$ & $14.73 \pm(0.44)$ \\
\hline 3 & $38.44 \pm(1.37)$ & $31.35 \pm(1.31)$ & $74.86 \pm(1.41)$ & $74.24 \pm(2.13)$ & $40.51 \pm(0.52)$ & $30.64 \pm(1.07)$ \\
\hline 4 & $61.02 \pm(1.90)$ & $51.96 \pm(3.69)$ & $99.19 \pm(1.31)$ & $95.34 \pm(0.70)$ & $60.25 \pm(1.46)$ & $50.47 \pm(0.48)$ \\
\hline 6 & $80.92 \pm(1.50)$ & $70.55 \pm(1.87)$ & & & $80.11 \pm(1.26)$ & $70.60 \pm(1.01)$ \\
\hline 8 & $99.10 \pm(1.59)$ & $90.01 \pm(1.05)$ & & & $99.11 \pm(0.77)$ & $89.89 \pm(0.44)$ \\
\hline 10 & & $98.89 \pm(0.71)$ & & & & $99.26 \pm(1.00)$ \\
\hline
\end{tabular}

SD: Standard deviation

Table 7: Drug release kinetics study

\begin{tabular}{|c|c|c|c|c|c|c|}
\hline Kinetic model & F1 & F2 & F3 & F4 & F5 & F6 \\
\hline \multicolumn{7}{|l|}{ Zero order } \\
\hline K0 & 10.83 & 13.16 & 24.37 & 24.06 & 13.06 & 10.88 \\
\hline $\mathrm{R}^{2}$ & 0.973 & 0.980 & 0.993 & 0.997 & 0.983 & 0.975 \\
\hline \multicolumn{7}{|l|}{ First order } \\
\hline K1 & -0.093 & -0.180 & -0.463 & -0.313 & -0.231 & -0.191 \\
\hline $\mathrm{R}^{2}$ & 0.929 & 0.873 & 0.756 & 0.873 & 0.814 & 0.847 \\
\hline \multicolumn{7}{|l|}{ Higuchi plot } \\
\hline $\mathrm{R}^{2}$ & 0.890 & 0.904 & 0.948 & 0.929 & 0.9 & 0.902 \\
\hline \multicolumn{7}{|c|}{ Korsmeyer-Peppas } \\
\hline KK & 0.0008 & 0.013 & 0.019 & 0.004 & 0.014 & 0.0002 \\
\hline $\mathrm{N}$ & 1.174 & 1.009 & 1.110 & 0.988 & 1.026 & 1.32 \\
\hline $\mathrm{R}^{2}$ & 0.979 & 0.952 & 0.970 & 0.996 & 0.949 & 0.969 \\
\hline
\end{tabular}

Table 8: Formulation of mini-tablets (content per two mini-tablets)

\begin{tabular}{|c|c|c|c|c|c|c|c|}
\hline Batch No. & $\begin{array}{l}\text { Montelukast } \\
\text { sodium (mg) }\end{array}$ & Carnauba wax (mg) & GMS (mg) & $\begin{array}{l}\text { Rice bran } \\
\text { wax (mg) }\end{array}$ & $\begin{array}{l}\text { Microcrystalline } \\
\text { cellulose (mg) }\end{array}$ & Aerosil 200 (mg) & Talc (mg) \\
\hline F1 & 10 & 10 & & & 3 & 2 & 1 \\
\hline $\mathrm{F} 2$ & 10 & 20 & - & - & 3 & 2 & 1 \\
\hline F3 & 10 & - & 10 & & 3 & 2 & 1 \\
\hline $\mathrm{F} 4$ & 10 & - & 20 & & 3 & 2 & 1 \\
\hline F5 & 10 & & & 10 & 3 & 2 & 1 \\
\hline F6 & 10 & & & 20 & 3 & 2 & 1 \\
\hline
\end{tabular}

Table 9: Interpretation of angle of repose

\begin{tabular}{ll}
\hline Repose angle $\left({ }^{\circ}\right)$ & Flowability \\
\hline $25-30$ & Excellent \\
$31-35$ & Good \\
$36-40$ & Fair \\
$41-45$ & Passable \\
$46-55$ & Poor \\
$56-65$ & Very poor \\
$>66$ & Very very poor \\
\hline
\end{tabular}

from natural origin and showed good compressibility under moderate pressures. The tablet weight is adjusted compression, such that each tablet contains about $1 \mathrm{mg}$ of active principle. The tablets formed had enough strength to withstand rigors of the postcompression tests and processes like packaging.

The dissolution profile of the formulations as shown in Table 6 endorsed the influence of nature of ingredients used as matrix formers. It can be easily inferred from Fig. 1 that the rate of drug dissolution is slower where carnauba wax and rice bran wax but the rate retardation is less may be due to small size of the tablets.

The release kinetics data when fitted as shown in Table 7, to different kinetic models, zero-order drug release was predominant as reflected form the regression values given for each equation.

Mechanism of drug release obtained by Korsmeyer-Peppas model was super Case II transport type. This is due to Fickian diffusion taking 
Table 10: Interpretation of drug transport mechanism from release exponent

\begin{tabular}{|c|c|c|}
\hline Release exponent & Drug transport mechanism & Rate $d M_{t} / d_{t}$ as a function of time \\
\hline 0.5 & Fickian diffusion & $t^{0.5}$ \\
\hline $0.5<\mathrm{n}<1.0$ & $\begin{array}{l}\text { Anomalous (non-Fickian) } \\
\text { transport }\end{array}$ & $t^{\mathrm{n}-1}$ \\
\hline$n=1$ & Case II transport & $\begin{array}{l}\text { Zero-order } \\
\text { (time independent) release }\end{array}$ \\
\hline $\mathrm{n}>1.0$ & Super Case II transport & $t^{\mathrm{n}-1}$ \\
\hline
\end{tabular}

Table 11: Flow properties of formulation by Carr's index and Hausner's ratio

\begin{tabular}{|c|c|c|c|c|c|}
\hline Formulations & Bulk* density & Tapped* density $\left(\mathrm{g} / \mathrm{cm}^{3}\right)$ & Carr's index ${ }^{\#}(\%)$ & Hausner's ratio ${ }^{\#}$ & Flowability ${ }^{\circledR}$ \\
\hline $\mathrm{F} 1$ & $0.3946 \pm 0.47$ & $0.4969 \pm 4.1$ & 20.59 & 1.26 & Passable \\
\hline F2 & $0.371 \pm 0.43$ & $0.4928 \pm 0.8$ & 24.59 & 1.33 & Passable \\
\hline F3 & $0.3715 \pm 0.22$ & $0.4925 \pm 1.8$ & 24.57 & 1.33 & Passable \\
\hline $\mathrm{F} 4$ & $0.3986 \pm 2.03$ & $0.5168 \pm 0.5$ & 22.87 & 1.30 & Passable \\
\hline F5 & $0.3848 \pm 2.13$ & $0.4917 \pm 1.1$ & 21.74 & 1.28 & Passable \\
\hline F6 & $0.3647 \pm 2.14$ & $0.4525 \pm 0.6$ & 19.40 & 1.24 & Passable \\
\hline
\end{tabular}

*The values in the table designate average values of $n=6$ with \pm standard deviation values, ${ }^{\#}$ values are calculated as on the basis of average values, ${ }^{\circledR i n t e r p r e t a t i o n ~ i s ~}$

based on average values of Carr's index and Hausner's ratio

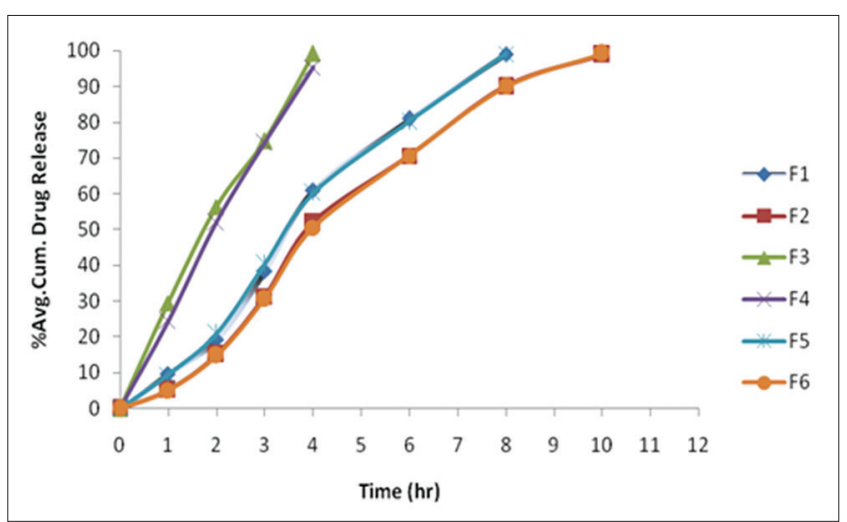

Fig. 1: Average \% cumulative drug release profiles of mini-tablets

place along with the erosion of matrix with time. The erodible matrixes form channels for release of drug during course of dissolution studies. Hence, the drug release commences with diffusion as the predominant mechanism of drug release and then with the course of study, diffusion takes place along with the erosion of matrix that allows accelerated release of the drug.

\section{CONCLUSION}

Wax matrix formers, viz., glyceryl monostearate, purified rice bran wax, and carnauba wax were used in formulation of sustained release minitablets. The matrix-formers allowed formulation of mini-tablets with desirable characteristics. The drug release studies showed that the release over a period of $10 \mathrm{hrs}$ was achieved with carnauba wax and rice bran wax. Further delay in release was not achieved may be due to small size of the tablet.

\section{REFERENCES}

1. Rosiaux Y, Jannin V, Hughes S, Marchaud D. Solid lipid excipients - Matrix agents for sustained drug delivery. J Control Release 2014;188:18-30.

2. Sujja-areevath J, Munday J, Cox PJ, Khan KA. Release characteristics of declofenac sodium from encapsulated natural gum mini-matrix formulations. Int J Pharm 2005;139:53-62.

3. Thomsom Healthcare. Physician's Desk Reference. $62^{\text {nd }}$ ed. Montvale, NJ: Thomson Healthcare Inc.; 2008. p. 1926.

4. Alderborn G. In: Aulton ME, editor. Pharmaceutics, The Science of Dosage form Design. $2^{\text {nd }}$ ed. London: Harcourt Publishers Limited; 2002. p. 397-440.

5. Porter CJH, Charman WN. In vitro assessment of oral lipid based formulation. Adv Drug Deliv Rev 2001;50:S127-47.

6. Shaik RV, Yi-Hsu J, Thengumpillil NB, Yaw-Terng C. A process for the preparation of food-grade rice bran wax and the determination of its components. J Am Oil Chem Soc 2005;82(1):57-64.

7. Patil BS, Kulkarni U, Bhavik P, Soodam SR, Korwar PG. Formulation and evaluation of mouth dissolving tablets of nimesulide by new coprocessed technique. J Pharm Chem Biol Sci 2010;4 Suppl 1:587-92.

8. Panda TK, Das D, Panighahi L. Development of multiple-unit mucoadhesive sustain release mini-tablets of bosentan. Int J Pharm Pharm Sci 2016;8 Suppl 10:235-41.

9. Daharwal S, Jangde R, Saraf S, Saraf S. Taste masking method for bitter drug and tasteless dispersible tablet: An overview. Famvita Net J 2008;4:1-3.

10. Morita Y, Tsushima Y, Yasui M, Termoz R, Ajioka J, Takayama K. Evaluation of the disintegration time of rapidly disintegrating tablets via a novel method utilizing a CCD camera. Chem Pharm Bull (Tokyo) 2002:50:1181-6.

11. United States Pharmacopoeia. The Official Compendia of Standards. First Annual ASIAN ed. Rockville, MD: United States Pharmacopoeial Convention Inc.; 2002. p. 1981.

12. Arora P, Sethi V. Orodispersible tablets: A comprehensive review. Int J Res Dev Pharm Life Sci 2013;2 Suppl 2:270-84.

13. Mukherjee K, Chakraborty S, Biswanath SA. Quick/slow biphasic release of a poorly water soluble antidiabetic drug from Bi-layer tablets. Int J Pharm Pharm Sci 2015;7 Suppl 11:250-8.

14. Higuchi T. Rate of release of medicaments from ointment bases containing drugs in suspension. J Pharm Sci 1961;50:874-5.

15. Korsmeyer RW, Gurny R, Doelker E, Buri P, Peppas NA. Mechanisms of solute release from porous hydrophilic polymers. Int J Pharm 1983;15(1):25-35

16. Peppas NA. Analysis of Fickian and non-Fickian drug release from polymers. Pharm Acta Helv 1985;60(4):110-1.

17. Peppas NA, Sahlin JJ. A simple equation for the description of solute release. III coupling of diffusion and relaxation. Int J Pharm 1989;57:169-72. 